\title{
The Attitudes of Social Responsibility Students at JUST Towards Voluntary Work and the Challenges They Face
}

\author{
Najwa Darawsheh ${ }^{1 *} \quad$ Hazem Badarneh ${ }^{2} \quad$ Ahmed AL-Shoha $^{3}$ \\ 1.Assistant Professor/Jadara University, Jordan \\ 2.Part-time Lecturer / Irbid University College, Jordan \\ 3.Yarmouk University / Model School, Jordan
}

\begin{abstract}
The study aimed to reveal the attitudes of social responsibility students at JUST toward voluntary work and the challenges they face in practicing it. The researcher used a descriptive survey method and a questionnaire as a study tool. The study sample consisted of (400) students. The results of the study indicated that the attitudes of social responsibility students at JUST toward voluntary work and the challenges they face in practicing it was " high", and the most important challenges that students face in practicing voluntary work are as follows: the time of volunteering interfered with the time of study, the poor economic level of some student families, the weak contribution of courses to the preparation of student leaders who lead voluntary work. The results also showed that there are statistically significant differences in the responses of the respondents on the attitudes of students of social responsibility attributable to the effect of the gender variable in favor of the female students, and the are no statistically significant differences attributed to the effect of the number of members of the population.
\end{abstract}

Keywords: voluntary work, challenges, student attitudes, Jordan University of Science and Technology (JUST). DOI: $10.7176 / \mathrm{JEP} / 11-5-11$

Publication date: February $29^{\text {th }} 2020$

\section{Introduction}

Volunteering is one of the criteria that indicates the level of awareness of society and its service. As known advanced society is distinguished from another by the opportunities it provides for volunteers, whether inside or outside its institutions. Volunteering continues to be the cornerstone of community building, spreading love and social connectivity among the members of society.

Volunteering as defined by Rahal (2006) is a humanitarian action that is closely related to all the meanings of good and good work. It is one of the most important ways of contributing to the advancement of the status of the community today, which is gaining increasing importance day after day, especially with the widening gap between available resources and people's needs .

Volunteering is a human practice closely linked to all the meanings of good and good work for humanity, but it may vary from one society to another, and from time to time, in terms of its scope, form, attitudes and motives. Its scale varied depending on the peaceful times of society. Where voluntary work increases in times of war, crisis and natural disasters, depending on the seriousness of the situation. In terms of its forms, it can be manual effort, professional effort or in the form of a donation. Volunteering attitudes can be spontaneous or directed by the state to undertake social, educational or development activities. It can be done out of religious, social, psychological, and economic motives (Shuman,2012.)

Because of its positive impact on the individual and society, voluntary work is closely associated with Islam, and for Muslims it constitutes a competition to win the reward of Almighty God, as stated in the holy Quran "And cooperate in righteousness and piety, but do not cooperate in sin and aggression." (Al Ma'idah:2). And in Surat Al Insan: 9 "We feed you only for the countenance of Allah . We wish not from you reward or gratitude." The prophet peace be upon him said: "if one relieves a Muslim of his troubles, Allah will relieve his troubles on the Day of Resurrection" (Al- Bokhari, 2003.)

There are numerous Qur'anic verses and prophetic hadiths focus on the virtue of charity and good deeds, calling for spending money, helping others, making efforts and allocating time to perform social service tasks.

The early knowledge of the value of volunteerism and charitable work was clearly witnessed in Islamic history, Muslims were innovative in exploring various ways and methods of social activity in which they invested their money, times and efforts in charity. These included feeding the hungry and giving drinks to the thirsty, providing clothing and shelter to the needy, and fostering care for the orphans and widows.

Islamic Sharia stipulated the value of community care by giving al Zakat of money and crops to the poor, treating neighbors with compassion, curing the ill, caring for the elderly. In addition, the voluntary work in Islam is represented by the Muslim behavior when collecting money for the needy, removing the harmful objects from the road, planting trees ( Al-Ghamdi, 2010.)

Nationally, in 1967 the United Nations Development Program launched the program " United Nation Voluntary Program" and in December 1968, the United Nations General Assembly adopted Resolution No. 
(2460) which called the Social and Economic Council to study the possibility of establishing an international body for volunteers.

In 1971, the formation of the program was approved by Resolution No. (2659) and in 2001, the international community adopted an international year for volunteers worldwide to address their role in voluntary work in the health, social and environmental fields ( Abu Al-Naser, 2016.)

Young people have a high mental and physical capacity, which is why many countries have sought to invest their efforts and encourage them to develop a culture of volunteerism. The importance of youth engagement in voluntary work comes from strengthening young people's connection with their homeland, developing young people's intellectual, creative, science and practical skills and capabilities, and providing them with broad opportunities to express their views on issues that concern their society (Al-Sultan, 2009.)

Universities in different countries have endeavored to embrace voluntary work, provide voluntary skills to students and develop students' attitudes towards it. Some universities even devoted volunteering courses focusing on the two sides: theoretical and applied. University students are considered by the nature and characteristics of the youth stage to be one of the most likely categories of candidates to do voluntary work here comes the role of the university as one of the important social educational institutions entrusted by society with the task of carrying out their children's education. Its role in activating voluntary work is consistent with its pioneer role in community leadership which is demonstrated in its three basic functions : teaching, scientific research, and community service (Al-Otaibi, 2016.)

To invest the role of university students in volunteering, Al Nabulsi (2010) indicated several measures including: searching for educational methods and activities to develop the spirit of voluntary work for university student, developing the educational process to eliminate the negativity and indifference among university students, allocating part of the student performance assessment to voluntary projects and voluntary community work and give priority to young volunteers in obtaining public and private sector jobs.

\subsection{Benefits of volunteering:}

Al-Zubaidi (2006) listed the benefits university students obtain through their voluntary work, as voluntary work creates opportunities for university youth to take advantage of their ability and energy to serve the needy in their community. Volunteering leads to a reduction in disparities in social class, helps coordinate and spend the leisure time of students in teamwork that increases their respect for work.

Voluntary programs lead to many benefits for the university student including promoting commitment, religious and national affiliation, accustoming the student to life planning and developing life skills in dealing with life stress.

Students can obtain psychological and social satisfaction through voluntary activities; they can express their views in general and social issues, promote their social responsibility and learn about the needs of the market and how to deal with it.

\subsection{Obstacles facing volunteering in universities}

Voluntary work in universities faces various obstacles that present students with a challenge and hinder their participation in it. Al-Arab (2012) indicated that There are many reasons to limit the involvement of individuals in voluntary work, including: underestimation of individuals, differentiation between males and females, lack of awareness of the importance of voluntary work as a result of the lack of government and non-governmental institutions ' voluntary work guidance programs. The dominance of a group of people over voluntary centers with preventing individuals to take part in decision-making which makes them feel as if they are a tool for implementing the work of the programs of this group.

Meliji (1997) claimed that the most critical challenges facing voluntary activity were the political and social environment in society, which often places constraints on voluntary work as well as conflict between voluntary activity and the time of volunteers. Another source of obstacles to voluntary work is lack of knowledge, expertise and understanding of the value of voluntary work.

Hilalat (2018) and Kandari (2016) said that the obstacles facing volunteering are: limiting the voluntary activity on people who have experience and competence towards volunteering and who works in voluntary centers. The absence of voluntary centers in some compound, the distant between these centers and the place where the volunteers live, and the lack of funding plays a major role in attracting volunteers.

Al-Otaibi (2016) cited two types of reasons for young people's reluctance to participate in voluntary work, including A) university-related reasons such as students being busy studying, the difficulty of balancing study and voluntary work and lack of reinforcement by the university administrator towards volunteering. B) personal reasons, such as lack of interest in voluntary work, are not currently on of their priorities and lack of awareness of the concept of voluntary work and its association with religion.

Al-Bakkar, Al-Nabulsi and Al-Adayleh (2017) divided the hurdles to volunteering in universities into two types: student-related hurdles and university-related hurdles. Student-related hurdles are the lack of free time to 
practice volunteering, the lack of training in voluntary work, the fear of responsibility among students and the lack of knowledge in voluntary work fields. Where the university-related hurdles include the following: The curriculum does not emphasize the voluntary work, the lack of university support for voluntary work, the lack of student faculty members ' awareness of the importance of volunteering, and the university does not organize volunteer days all through the academic year.

Many previous studies dealt with voluntary work in universities such as Abu Iyada (2018) conducted a study in the Sultanate of Oman aimed at identifying the attitudes of university students towards voluntary services in the Sultanate of Oman as well as identifying obstacles that prevent them from participating in voluntary services. The study used the survey methodology. The study sample consisted of (500) male and female students. The questionnaire was used as a study instrument. The results revealed a decrease in the number of voluntary students. It also revealed that sports and cultural organizations are the main beneficiaries of student voluntary activities as well as local agencies. The study found that the motives for volunteering are also significant motivating factors: the religious aspect, the promotion of national affiliation, the urge to fill leisure time and the acquisition of work experience.

The results also indicated that the students ' justifications for doing voluntary work included activities that work on their self-development and raise their job skills, and the lack of time, the study burden that prevents them from participating actively in voluntary activities, are among the obstacles that students mentioned.

Al-Hussein (2017) study aimed at revealing the attitudes of students of the College of Education at King Saud University towards voluntary work and its relationship to the mental health level of students, the study sample consisted of (202) students, two measures were applied: the voluntary work scale and the mental health scale. The results indicated that the level of attitudes of female students of the College of Education towards voluntary work is very high, and That there isn't any significant correlation between the volunteer and mental health patterns among College of Education students.

Dyson, Akker \& O'Driscoll (2017) conducted a study in the United States of America aimed at uncovering nursing students' attitudes toward volunteering at the University of Middlesex. The study followed a mixed methodology, where a questionnaire consisting of (24) open questions was applied to (137) male and female students, and qualitative interviews were conducted by (14) male and female students from the voluntary program coordinators at the university. The results of the study showed that there was a low level of voluntary participation among students, despite their positive attitudes towards voluntary work due to the requirements of time and study. The results showed that voluntary work had a positive impact on the student by developing capabilities, improving self-esteem and developing personal values.

Curl and Benner (2017) conducted a study in Kentucky, USA, aimed at exploring the impact of volunteerism on improving student social experiences and attitudes toward it. The study followed a descriptive survey methodology through (67) students who were intentionally selected from the College of Social Work at the University of Kentucky. The sample replied to an electronic questionnaire consisting of (15) items distributed within the Likert scale of five points. The results of the study showed that voluntary work had a significant positive impact on the student's academic and social experiences and that the student's participation in voluntary social work programs increases their positive attitudes towards voluntary work and towards society in general.

Al-Bakkar, Al-Nabulsi and Al-Adayleh (2017) study aimed at identifying the obstacles to volunteering among university students at the University of Jordan through the university students, community culture, the environment and social institutions. The study sample consisted of (189) students chosen through a comprehensive survey method. The results showed that the student-related obstacles were the lack of training for students to practice voluntary work, the ignorance of places suitable for voluntary work and barriers related to community culture as the society does not give volunteers a high value. The most important barriers related to social institutions are represented in the lack of interest of workers in social institutions in volunteering and volunteer students.

McKeown (2015) conducted a study in the United Kingdom aimed at revealing whether the participation of law students in the free service at the university improves their attitudes towards participating in voluntary work. The study used a descriptive methodology through a random sample of (200) law students at the university who answered a questionnaire consisting of (22) open questions about free service programs, voluntary work and attitudes towards it. The results of the study indicated the students highly appreciate participating in free service, especially legal services, and that voluntary work programs increase their professional and life experience. The results also indicated that students' legal and social skills become more effective after their participation in every voluntary program offered by the university.

Darwesh (2015) study aimed to identify the attitudes of a random sample of male and female university students in the Gaza Strip towards voluntary work, where a scale of attitudes toward volunteerism was built and ascertained its stability and consistency. It was applied to a sample of (600) male and female students from universities ( The Islamic University, Al-Quds Open University, Al-Azhar University and University). The 
results of the study revealed that the attitudes of university students towards voluntary work was positive and highly rated and that there were no statistically significant differences in the responses of the study sample individuals due to the gender variable and the place of residence variable.

\subsection{Comments on previous studies:}

The previous studies addressed university students ' attitudes towards voluntary work and their obstacles. These studies varied between Arab and foreign studies, most of which employed the quantitative survey method. The researchers have benefited from previous studies and theoretical literature in building the study instrument.

This study is similar to the previous studies in addressing the subject of voluntary work and its obstacles in universities and differs in terms of dealing with the two variables together. The researchers have also benefited from these studies in developing an information collecting instrument, identifying the results, comparing the results with the results of the current research and using appropriate statistical treatments to support certain theoretical framework-related opinion.

This study is distinguished from previous studies in its attempt to identify the attitudes of university students towards volunteering and the obstacles from the student's perspective.

\section{The study problem}

The Jordan University of Science and Technology ( JUST) is one of the universities that have adopted a course taught to the students from the scientific and humanitarian specializations. Social Responsibility Course is a compulsory course that focuses on the concept of social responsibility and voluntary work. This course includes mandatory students' involvement in voluntary work through group work and on certain criteria.

As lectures of this course, the researchers have encountered some positive aspects of this course about students ' personalities and attitudes to volunteering and helping others. Based on the above, the problem of this study is identification of the attitudes of students of the social responsibility course at JUST towards voluntary work, and the obstacles that face them in practicing it. The study tried to answer the following questions:

- What are the attitudes of students of the social responsibility course at JUST towards volunteering from their perspective?

- What are the obstacles facing students of the social responsibility course at JUST in practicing voluntary work from their perspective?

- Are there any statistically significant differences at the level of significance $(\alpha=0.05)$ between the study sample members ' average responses to voluntary work due to variables: gender, place of residence, number of family members and income?

\section{The objectives of the study}

This study aimed at:

- Identifying the attitudes of students of the social responsibility course at JUST towards volunteering from their perspective.

- Identifying the obstacles that students of the social responsibility course at JUST face in practicing voluntary work.

- Disclosing the differences between the averages of the responses of the members of the study sample towards voluntary work according to variables: gender, place of residence, number of family members and income?

\section{The importance of the study}

The research derived its significance from the relevance of the subject it discusses and the goals it aims to achieve, since the issue of volunteering and helping others is one of the factors for societies ' advancement and distinctive.

- The importance given to voluntary work by the Holy Qur'an and the Prophet's noble Sunnah and considering helping others and meeting their needs as one of the greatest deeds a Muslim can do.

- It is important to develop the stage of youth as they are the cornerstone of society as their development depends on their society.

- What the study will reveal about students 'attitudes towards voluntary work and its fields, and the obstacles that hinder the practice of volunteerism.

- University administrators can use the findings of this study in developing the course of social responsibility according to the experiences of some universities.

- The course lecturers themselves benefited from implementing approaches that help increase understanding among students of the value of volunteerism and its cultural and legal necessity. 


\section{Definitions}

- Voluntary work:

Al-Rashideh, (2016) described it as "a humanitarian action in which the individual interpret his sincere desire to support his community and human societies with the material, intellectual and capacity possibilities that he possesses, in order to help resolve a humanitarian or individual crisis or to enhance a public benefit without a return. " Researchers describe voluntary work procedurally as a collection of individuals efforts and acts towards others as well as social, physical or intellectual efforts without seeking financial compensation. With the motivation of seeking reward from God Almighty.

- Social Responsibility Course:

It is a mandatory course for all students at JUST. This covers two specific topics: the idea of social responsibility and its values and voluntary work and the second subject, the Jordanian social, political and economic structure. In 2016, this course was introduced based on two dimensions, one theoretical and the other applied inside and beyond the University.

\section{Study limits:}

This study is limited to students of JUST for the academic year (2019/2020). Which limits the generalization of the results of the current study to the researchers ' objectivity in carrying out this study and in the application process, and the study sample's seriousness in responding to the study instrument. In addition to the availability of the study instruments psychometric features related to reliability and validity.

\section{Methods and procedures}

It includes a description of the methodology of the study, population of study, sample, selection of the sample and instrument, validity and reliability methods used, and procedures.

\subsection{Study method: the descriptive survey method was employed.}

7.2 Study population: It consists of (1179) male and female students who study the course of social responsibility and volunteerism during the first academic year (2020/2019) at the University of Science and Technology ( JUST) in northern Jordan.

7.3 The study sample: The sample of the study was selected randomly that is represented by the study population of (400) male and female students during the school year (2019/2020), with a percentage of (38\%) of the study population. (450) questionnaires were distributed, and (300) questionnaires were retrieved with ratio of (94\%). Table (1) shows the distribution of the study sample according to the independent variables.

Table 1. Distribution of the members of the study sample according to the levels of their variables

\begin{tabular}{|l|l|l|l|}
\hline & Categories & Frequency & Ratio \\
\hline \multirow{2}{*}{ Gender } & male & 160 & 40.0 \\
\cline { 2 - 4 } & female & 240 & 60.0 \\
\hline \multirow{2}{*}{ Place of residence } & city & 278 & 69.5 \\
\cline { 2 - 4 } & village & 122 & 30.5 \\
\hline \multirow{2}{*}{ No. family members } & Less than 5 & 38 & 9.5 \\
\cline { 2 - 4 } & More than 5 & 362 & 90.5 \\
\hline \multirow{2}{*}{ Income } & Less than 1000 JD & 217 & 54.3 \\
\cline { 2 - 4 } & More than 1000 JD & 183 & 45.8 \\
\hline & Total & 400 & $100 \%$ \\
\hline
\end{tabular}

\subsection{Study instrument:}

To achieve the objectives of the study, the researchers built an instrument aimed at identifying the attitudes of students of social responsibility at the JUST towards voluntary work and the obstacles facing students in its practice. It consists of (33) items distributed in three fields consisting of (goals, fields, and difficulties that faced the voluntary work)

\subsection{The validity and reliability of the study instrument}

The face validity of the instrument has been confirmed, as it has been presented to (10) expert arbitrators of the faculty members of the Colleges of Education of Jordanian Universities, who have been asked to study the subject of the questionnaire and to express their opinion in the degree of its clarity, cohesion and its suitability for the field to which it belongs. All the suggested modification has been implemented such as the addition, deletion, drafting, suggestion of new items and finally the questionnaire items have been accepted with (33) 
items. Accordingly, a standard of $80 \%$ of the arbitrators' agreement has been adopted on the instrument's items.

To confirm the reliability of the study instrument, the test-retest method was verified after two weeks on a group from outside the study sample consisting of (30) male and female students, and then The Pearson correlation coefficient on the overall study tool was calculated between the two periods. The reliability coefficient was also calculated by the method of internal consistency according to the Cronbach alpha equation as shown in Table (2). These values were considered appropriate for the purposes of this study.

Table 2. Alpha internal consistency coefficient Cronbach and Test- retest reliability (Pearson coefficient) for fields and the overall instrument

\begin{tabular}{|l|l|l|}
\hline Fields & Pearson coefficient & Cronbach alpha \\
\hline The objectives of volunteering & 0.84 & 0.82 \\
\hline Areas of voluntary work & 0.87 & 0.86 \\
\hline Obstacles facing volunteering & 0.90 & 0.88 \\
\hline Overall Total & 0.86 & 0.85 \\
\hline
\end{tabular}

\subsection{Correction of the instrument}

The Likert five-points scale was employed to correct the study instruments, by giving each of its items one of the five degrees (very high, high, moderate, low, and very low) represented digitally $(5,4,3,2,1)$, respectively. The following scale has been adopted for the purposes of analyzing results

Table 3. The statistical standard for identifying attitudes toward volunteering among students of JUST

\begin{tabular}{|l|l|}
\hline Means & Degree \\
\hline from 1.00 and less than 1.80 & Very low \\
\hline from 1.80 and less than 2.60 & low \\
\hline from 2.60 and less than 3.40 & moderate \\
\hline from 3.40 and less than 4.20 & high \\
\hline From 4.20 and less than 5.00 & Very high \\
\hline
\end{tabular}

7.7 Study variables:

Study variables include the following:

- Demographic variables, which are as follows:

A. The independent variables:

- Gender: (Male, Female).

- Place of residence (city, village).

- Number of family members: ( less than 5 members or 5 members and more)

- Income: less than $1500 \mathrm{JD}$ and $1500 \mathrm{JD}$ or more.

B. The dependent variable,

Attitudes of students in the social responsibility course towards volunteering.

\section{Discussion of results}

1- Results of the first question: What are the attitudes of students of the social responsibility course at JUST towards volunteering from their perspective?

To answer this question, means and standard deviations of the attitudes of the study sample towards voluntary work were extracted as shown in Table (4)

Table 4. Means and standard deviations of the attitudes of the study sample towards voluntary work, arranged in descending order according to the means.

\begin{tabular}{|l|l|l|l|l|l|}
\hline Rank & No. & Fields & means & SD & Attitudes \\
\hline 1 & & Objectives of volunteering & 4.09 & .740 & High degree \\
\hline 2 & & Areas of voluntary work & 3.79 & .797 & High degree \\
\hline \multicolumn{2}{|l}{ The overall total } & 3.93 & .666 & High degree \\
\hline
\end{tabular}

Table (4) shows that the fields of students' attitudes toward voluntary work in the course of social responsibility at JUST was high. Where the means ranged between (3.93-4.09). The field of the objectives of volunteering came first with a mean of (4.09) and a high degree, where the fields of voluntary work came second with a mean (3.79) and high degree. The overall total was (3.93). This result is consistent with the study results of Abu Iyada (2018), Hussain (2017), Dyson, Akker \& O'Driscoll (2017), McKeon 2015, and Darwesh (2015) That indicated the presence and high degree of Positive attitudes of male and female students towards voluntary work. This may due to the nature of males' and females' socialization culture which call for helping others. The course of social responsibility plays a role in enhancing the attitudes of students towards volunteering, particularly the theoretical side. Every male and female student is required to engage in voluntary work within or 
outside the university. Averages and standard deviations were calculated for the estimates of the study sample on each of the items of each field of the instrument.

\subsection{The discussion of the results according to the fields:}

1.The objectives of volunteering

Table 5. Means and standard deviations for the items of the field " the objectives of volunteering" in descending order

\begin{tabular}{|l|l|l|l|l|l|}
\hline Rank & $\begin{array}{l}\text { No. } \\
\text { Items }\end{array}$ & Items & Means & SD & Level \\
\hline 1 & 3 & I seek reward from volunteering & 4.36 & 1.029 & $\begin{array}{l}\text { Very } \\
\text { high }\end{array}$ \\
\hline 2 & 6 & Volunteerism promotes self-confidence & 4.18 & .999 & high \\
\hline 3 & 1 & Volunteering develops teamwork & 4.15 & .942 & high \\
\hline 4 & 4 & Volunteering helps to get to know more friends & 4.12 & 1.050 & high \\
\hline 5 & 8 & Volunteering develops social communication skills & 4.10 & 1.005 & high \\
\hline 6 & 2 & Volunteerism fosters a sense of social responsibility & 4.07 & .956 & high \\
\hline 7 & 5 & $\begin{array}{l}\text { Voluntary work contributes to occupying leisure time } \\
\text { with what is useful }\end{array}$ & 4.06 & 1.034 & high \\
\hline 8 & 7 & Volunteering strengthens individuals' national affiliation & 3.93 & 1.104 & high \\
\hline 9 & 9 & Volunteering helps in solving community problems & 3.83 & 1.104 & high \\
\hline
\end{tabular}

Table (4) indicates that item No. (3) "I seek reward from volunteering." Has recorded the highest mean = 4.36 and with a very high degree, while the rest of the items got averages that ranged between (3.83-4.18) with high degree. Item (9) "Volunteerism helps in solving community problems" has the lowest average $=3.83$ and a degree. Item (3) has the highest mean because volunteering was originally based on providing help and assistance to others without regard to financial returns. All Quranic verses and the prophet Hadith focus on seeking only reward when helping the needy.

This finding of this field is consistent with the results of the Abu Iyada (2018) study which revealed that the most important reason for volunteering is the faith dimension. Where the rest of the items obtained means with a high degree, they are also consistent with the findings of the Abu Ayyadah (2018) study indicating that the motives for volunteering are, the ability to fill up free time and gain work experience.

\subsection{Areas of voluntary work}

Table 6. means and standard deviations for the items in the fields of areas of voluntary work arranged in descending order

\begin{tabular}{|l|l|l|l|l|l|}
\hline Rank & No. & Item & Means & SD & Degree \\
\hline 1 & 10 & I would like to help people with special needs in society & 4.28 & .991 & $\begin{array}{l}\text { Very } \\
\text { high }\end{array}$ \\
\hline 2 & 11 & I tend to care for orphan children & 4.22 & .995 & $\begin{array}{l}\text { Very } \\
\text { high }\end{array}$ \\
\hline 3 & 16 & I tend to participate in preserving the environment & 3.94 & 1.112 & high \\
\hline 4 & 14 & I love taking care of and helping elderly people & 3.89 & 1.155 & high \\
\hline 5 & 17 & I would like to donate blood & 3.85 & 1.239 & high \\
\hline 6 & 13 & $\begin{array}{l}\text { I tend to educate school students about the negative effects of } \\
\text { smoking }\end{array}$ & 3.70 & 1.248 & high \\
\hline 7 & 12 & I seek to educate university students about the danger of drugs & 3.65 & 1.197 & high \\
\hline 8 & 18 & I like to participate in cleaning the facilities inside the university & 3.65 & 1.282 & high \\
\hline 9 & 19 & $\begin{array}{l}\text { I tend to participate in educating university students about extremist } \\
\text { thought and its effects }\end{array}$ & 3.59 & 1.289 & high \\
\hline 10 & 15 & I tend to participate in organizing traffic & 3.16 & 1.428 & high \\
\hline
\end{tabular}

As shown in Table $(6)$ items $(10,11)$ which stated, "I would like to help people with special needs in society" and "I tend to care for orphan children" records averages of $(4.28-4.22)$ respectively and with a very high degree. Where the rest of the items has an average ranged between (3.16-3.94) and with a high degree. Item (15) "I tend to participate in organizing traffic " got the lowest average of (3.16) and a high degree.

The study results related to assisting individuals with special needs and orphans revealed the presence of values among the study sample that made them appreciate these two groups as they always need assistance. Mosque preachers may also have a role in alerting people with special needs and orphans, this value is also witnessed in their places of worship and their areas of residence. This does not mean that the rest of the fields are 
insignificant as they also came with high degree. This result of this field is consistent with Al-Sultan (2009) which indicated that the most important areas that students want to volunteer in are: helping and caring for the poor and needy and visiting patients. And in showing that male university students have attitudes towards Volunteering participating in humanitarian relief, caring for the disabled and preserving the environment.

8.3 Results of the second question: What are the obstacles facing students of the social responsibility course at JUST in practicing voluntary work from their perspective?

To answer this question, means and standard deviations were calculated for the responses of the study sample about the obstacles facing the practice of volunteering as illustrated in Table (7)

Table 7. Means and SD for the items of the field of obstacles facing students in practicing volunteering, in descending order.

\begin{tabular}{|l|l|l|l|l|l|}
\hline Rank & No. & Items & Means & SD & Difficulty \\
\hline 1 & 31 & Poor incentives for volunteer students & 3.87 & 1.200 & high \\
\hline 2 & 21 & Volunteer times conflict with study times & 3.84 & 1.213 & high \\
\hline 3 & 30 & The poor economic level of the families of some students & 3.79 & 1.141 & high \\
\hline 4 & 24 & $\begin{array}{l}\text { The student's lack of knowledge of the associations and } \\
\text { organizations supporting volunteering }\end{array}$ & 3.76 & 1.180 & high \\
\hline 5 & 23 & Lack of supporters of voluntary work & 3.67 & 1.267 & high \\
\hline 6 & 28 & $\begin{array}{l}\text { The absence of the media's role in raising awareness of the } \\
\text { importance of volunteering }\end{array}$ & 3.65 & 1.238 & high \\
\hline 7 & 32 & $\begin{array}{l}\text { The weak contribution of the courses in preparing student } \\
\text { leaders to lead voluntary work }\end{array}$ & 3.62 & 1.176 & high \\
\hline 8 & 27 & $\begin{array}{l}\text { The poor understanding of some students of the nature of } \\
\text { voluntary work }\end{array}$ & 3.54 & 1.218 & high \\
\hline 9 & 29 & $\begin{array}{l}\text { The weak role of mosque preachers in raising awareness of } \\
\text { volunteering }\end{array}$ & 3.45 & 1.310 & high \\
\hline 10 & 25 & Weak encouragement of parents towards volunteering. & 3.37 & 1.328 & moderate \\
\hline 11 & 33 & $\begin{array}{l}\text { Weak encouragement of university lecturers towards } \\
\text { volunteering. }\end{array}$ & 3.29 & 1.302 & moderate \\
\hline 12 & 20 & Student fear of failure while doing voluntary work & 3.28 & 1.355 & moderate \\
\hline 13 & 26 & $\begin{array}{l}\text { There are some negative judgments in the community about } \\
\text { some volunteers }\end{array}$ & 3.26 & 1.390 & moderate \\
\hline 14 & 22 & Some believe that volunteering is a waste of effort and time & 2.86 & 1.480 & moderate \\
\hline
\end{tabular}

Table (7) illustrates that the items with ranks $(1,2,3,4,5,6,7,8,9)$ obtained means ranging between (3.45-3.87) and with a high degree, while the rest of the items record means ranged between (2.86-3.37) and with a high degree. On the other hand, item (22) "Some believe that volunteering is a waste of effort and time" got the lowest mean (2.86) and a moderate degree.

This may be attributable to the fact that, volunteering requires free time that does not conflict with studying or work times and the availability of the financial aspect of the volunteer, which enhances the effectiveness of his volunteering. We can't deny that a volunteer needs moral incentives that raise the level of his participation in voluntary work; God Almighty praised volunteer worshipers and the noble prophetic hadiths that show the reward of the volunteer Muslim in various areas of life.

8.4 The results of the third question: " Are there any statistically significant differences at the level of significance $(\alpha=0.05)$ between the study sample members ' average responses to voluntary work due to variables: gender, place of residence, number of family members and income?

To answer this question means and standard deviations were extracted from the responses of the study sample on voluntary work according to the study variables as shown in Table (8) . 
Table 8. Means and SD for the responses of the study sample according to the study variables

\begin{tabular}{|c|c|c|c|c|c|}
\hline & & & $\begin{array}{l}\text { Objectives } \\
\text { volunteering }\end{array}$ & $\begin{array}{l}\text { Areas of voluntary } \\
\text { work }\end{array}$ & $\begin{array}{l}\text { Overall } \\
\text { total }\end{array}$ \\
\hline \multirow[t]{4}{*}{ Gender } & male & mean & 4.04 & 3.62 & 3.82 \\
\hline & & $\mathrm{SD}$ & .761 & .758 & .640 \\
\hline & \multirow[t]{2}{*}{ female } & mean & 4.13 & 3.90 & 4.01 \\
\hline & & SD & .725 & .804 & .674 \\
\hline \multirow[t]{4}{*}{ Place of residence } & city & mean & 4.12 & 3.79 & 3.95 \\
\hline & & $\mathrm{SD}$ & .751 & .815 & .673 \\
\hline & \multirow[t]{2}{*}{ village } & mean & 4.02 & 3.79 & 3.90 \\
\hline & & $\mathrm{SD}$ & .712 & .758 & .652 \\
\hline \multirow{4}{*}{$\begin{array}{l}\text { No. of family } \\
\text { members }\end{array}$} & \multirow{2}{*}{$\begin{array}{l}\text { Less than } 5 \\
\text { members }\end{array}$} & mean & 4.02 & 3.89 & 3.95 \\
\hline & & SD & .677 & .789 & .606 \\
\hline & \multirow{2}{*}{$\begin{array}{l}5 \text { members or } \\
\text { more }\end{array}$} & mean & 4.10 & 3.78 & 3.93 \\
\hline & & $\mathrm{SD}$ & .747 & .798 & .673 \\
\hline \multirow[t]{4}{*}{ Income } & \multirow[t]{2}{*}{ Less than 1000} & mean & 4.16 & 3.75 & 3.95 \\
\hline & & $\mathrm{SD}$ & .712 & .825 & .671 \\
\hline & \multirow[t]{2}{*}{1000 or more } & mean & 4.00 & 3.84 & 3.92 \\
\hline & & SD & .765 & .762 & .663 \\
\hline
\end{tabular}

Table (8) shows an apparent variation in in the means and standard deviations of the responses of the study sample due to the variation in the levels of independent variables. Analysis of variance was used on the fields and the overall tool to indicate the significance of the statistical differences between the means as Table (8) illustrates.

Table 9. Analysis of variance of the effect of gender variables, place of residence, number of family members and income level

\begin{tabular}{|c|c|c|c|c|c|c|}
\hline $\begin{array}{l}\text { Source of } \\
\text { variance }\end{array}$ & Fields & $\mathrm{SS}$ & DF & MS & $\mathrm{F}$ value & $P$ value \\
\hline \multirow{3}{*}{ Gender } & Objectives of volunteering & 1.238 & 1 & 1.238 & 2.293 & .131 \\
\hline & Areas of voluntary works & 7.616 & 1 & 7.616 & 12.303 & .001 \\
\hline & Total & 3.919 & 1 & 3.919 & 8.947 & .003 \\
\hline \multirow{3}{*}{$\begin{array}{l}\text { Place of } \\
\text { residence }\end{array}$} & Objectives of volunteering & 1.556 & 1 & 1.556 & 2.882 & .090 \\
\hline & Areas of voluntary works & .142 & 1 & .142 & .229 & .632 \\
\hline & Total & .623 & 1 & .623 & 1.422 & .234 \\
\hline \multirow{3}{*}{$\begin{array}{l}\text { No. of family } \\
\text { members }\end{array}$} & Objectives of volunteering & .178 & 1 & .178 & .330 & .566 \\
\hline & Areas of voluntary works & .526 & 1 & .526 & .850 & .357 \\
\hline & Total & .033 & 1 & .033 & .075 & .784 \\
\hline \multirow{3}{*}{ Income } & Objectives of volunteering & 3.068 & 1 & 3.068 & 5.682 & .018 \\
\hline & Areas of voluntary works & .597 & 1 & .597 & .964 & .327 \\
\hline & Total & .179 & 1 & .179 & .409 & .523 \\
\hline \multirow{3}{*}{ Error } & Objectives of volunteering & 213.289 & 395 & .540 & & \\
\hline & Areas of voluntary works & 244.521 & 395 & .619 & & \\
\hline & Total & 173.003 & 395 & .438 & & \\
\hline \multirow{3}{*}{ Total } & Objectives of volunteering & 218.465 & 399 & & & \\
\hline & Areas of voluntary works & 253.406 & 399 & & & \\
\hline & Total & 177.221 & 399 & & & \\
\hline
\end{tabular}

Table (9) shows that there are significant differences attributable to the effect of the gender variable and came in favor of females, and that there aren't any differences attributable to the impact of variables (place of residence, income and number of family members). This result may be attributed to the level of awareness of students towards volunteering in terms of its objectives, importance, areas, and barriers hinder its practice, and thus no differences appeared in their responses according to the variables of the study. As for the existence of differences according to the gender variable in the fields of voluntary work and its objective in favor of females versus males, it may be due to the fact that female students are more proactive and more committed to doing voluntary work. This result was consistent with Darwesh (2015) finding that there were no differences based on the gender variable.

\section{Recommendations}

The researchers have recommended the following in light of the study results: 
- Developing a course on social responsibility to keep pace with developments in the field of voluntary work that focuses more on how to inculcate social responsibility in university students and set special standards for voluntary work in which students participate.

- Developing the performance of the lecturers of social responsibility courses by demonstrating the expertise and experience of some universities in the field of volunteering so that they can benefit from it in increasing the awareness of volunteering among their students.

- Providing moral incentives for students who participate in distinguished voluntary work inside and outside the university.

- Requesting preachers to focus on voluntary work and its benefits in their sermons, and to raise worshipers ' awareness of voluntary work.

\section{References}

Abu Al-Naser. M. (2016).Future Vision to Develop Voluntary Work in the Arab world. 1stEdit. Alexandria: modern University Library.

Abu Iyada, R. (2018). Students' Attitudes towards Voluntary Services: A Study of Dhofar University. Journal of Sociology and Social Work, 6(1), 73-80.

Al- Bokhari, M. (2003).Al-bokhari Book. Beirut: Ibn Kather Publishers.

Al-Arab.E. (2012).Image of Voluntary Work and its Organizations among University Youth according to international Attitudes. Social Affairs journal, 29(114), 9-43.

Al-Bakkar, A., Al-Adhyleh, L., \& Al-Nabulsi, H. (2017).Voluntary Work Obstacles among University Youth in Jordan University. University of Jordan. Human and social Sciences Journal, 44(1), 97-115

Al-Ghamdi, A. (2010).Voluntary social work from the perspective of Islamic education and its applications in high school. Unpublished Master Thesis, Umm Al-Qura University, Saudi Arabia.

Al-Harbi, H. (1418H). Standards of Voluntary Work: Islamic Educational vision. Paper presented to the first scientific conference, Umm Al-Qura University, Saudi Arabia.

Al-Hilalt, Kh. (2018), Obstacles of Voluntary Work in Jordan. Jordanian University of social Sciences, 11(1), $1-21$.

Al-Hussien, W. (2017).The trend towards voluntary work and its relationship to mental health among university students. Master Thesis, Naif Arab University for Security Sciences, Riyadh, Saudi Arabia.

Al-Jihni, M. (1418H). The role of institutions in voluntary services in the Kingdom of Saudi Arabia. Paper presented to the first scientific conference, Umm Al-Qura University, Saudi Arabia.

Al-Kandri, J. (2016). The culture of volunteering for basic education students in the State of Kuwait. Journal of Educational Sciences, 1 (1), 158-189.

Al-Miliji, A. (1997). Society Organization between theory and Practice. Alexandria: scientific Office of Computer for Publishing.

Al-Nabulsi, H. (2010). Role of University Youth in Voluntary Work and Political Participation.1st edit. Amman: Majdlawi Publishers.

Al-Otaibi, A. (2016). Activating Voluntary Work in Shaqra University. Specialized international Educational Journal, 5(11), 24-44.

Al-Rashideh, Z. (2016). Perceived Mental Image of Voluntary Work and its Relationship to Volunteerism Motivation among a sample from University of Nizwa students in the Sultanate of Oman in light of some variables. Master Thesis, University of Nizwa, Oman.

Al-Sultan, F. (2009).Male university youth attitudes toward voluntary work: An applied study on King Saud University. Bureau of Education for the Arab Gulf States, Riyadh.

Al-Zubaidi, F. (2006).Jordan University Students Attitudes towards voluntary Work. Unpublished Master Thesis, Jordan University. Jordan.

Bani Issa, M. (2018).Volunteerism and its Effects on Economic Development from an Islamic Perspective.1st edit. Oman: Dar Jalabi Al-Zaman.

Curl, A., \& Benner, K. (2017). Volunteering Enhances the Social Work Student Experience. Filed Educator, 7(2), 1-10.

Darwesh,S.(2015).Youth Attitudes towards the Voluntary Work in the Civil Organizations Study of the Condition of the Youth in Gaza Strip Governorates 1994 - 2009. Master Thesis, Islamic University, Gaza.

Dyson, S., Akker, O., \& O'Driscoll, M. (2017). The extent, variability, and attitudes towards volunteering among undergraduate nursing students: Implications for pedagogy in nurse education. Nurse Education in Practice, 23(1), 15-22

McKeown, P. (2015). Law student attitudes towards pro bono and voluntary work: The experience at North Umbria University. International Journal of Clinical Legal Education, 22(1), 1-40

Rahal, O. (2006). Youth and Voluntary Work in Palestine. Study Presented in Relief and Development 
Agency (al-Hayat).

Shuman, E. (2012). The social domains of voluntary work and its role in the process of social cohesion in Saudi society. a working paper presented at a symposium entitled Voluntary Work and Future Prospects, held at Umm Al-Qura University, on 28-29 / 10 /1434H.

The Holy Quran.

Zeeno, R. (2007). Voluntary work in Sunna: Objective Study. Master Thesis, Islamic University, Gaza. 